\title{
Nuclear Elongation Correlates with Neurite Induced Cellular Elongation During Differentiation of SH-SY5Y Neural Cells
}

\author{
El Alargamiento del Núcleo se Correlaciona con el Alargamiento Celular Inducido \\ por Neuritas Durante la Diferenciación de las Células Neuronales Sh-Sy5Y
}

Priya S. Balasubramanian ${ }^{1}$

BALASUBRAMANIAN, P. S. Nuclear elongation correlates with neurite induced cellular elongation during differentiation of sh-sy5y neural cells. Int. J. Morphol., 39(2):548-553, 2021.

SUMMARY: Cellular differentiation is a highly regulated process that has vast implications for the mechanics of the cell. The interplay between differentiation induced cytoskeletal mechanical changes and strain on the nucleus is a potential cause of gene level changes. This study explores mechanical changes in SH-SY5Y neural cells during differentiation mediated by Retinoic Acid (RA) across Days 0 through 9. Findings suggest that cellular elongation increases 1.92 -fold over a 10-day differentiation period, from $48.97 \pm 16.85 \mu \mathrm{m}$ to $93.96 \pm 31.20 \mu \mathrm{m}$ over 3 repeated trials and across multiple cells analyzed on ImageJ. Nuclear elongation increases less substantially from $17.51 \pm 2.71 \mu \mathrm{m}$ to $23.26 \pm 3.10 \mu \mathrm{m}$ over 3 repeated trials and across multiple cells. Results are statistically significant at a significance level of $\alpha=0.05$. This study is one of the first studies to show that during the process of RA mediated neural differentiation in SH-SY5Y neural cells, nuclear elongation is initially not significantly correlated with cellular elongation, but it becomes correlated during the differentiation process with an overall correlation coefficient of 0.4498 at a significance level of $\alpha=0.05$. Given the time course of the mechanical changes and the known coupling between the cytoskeleton and nuclear lamina, this study suggests a causative and correlative relationship between neurite-driven cellular elongation and nuclear elongation during neural differentiation.

KEY WORDS: Cell Differentiation; Nucleus; Cytoskeleton; Cell Mechanics; Imaging.

\section{INTRODUCTION}

Cell mechanics during differentiation is significant in determining cell fate. A mechanistic understanding of how strain created within the cell can influence cellular processes is crucial to furthering the current understanding of differentiation. It is well-established that cell mechanics and nuclear processes strongly influence each other. There are many pioneering biomaterials studies that focus on the interplay between cell and substrate, showing that substrate interactions influence cell mechanics, both through gene level and direct mechanical effects, and that this in turn influences gene expression (Peng et al., 2011; Zhang et al., 2018). Similarly, cell differentiation creates unique stress profiles on cells, and the quantification of the influence of these mechanical changes on chromatin structure will be instrumental in elucidating the mechanical basis for gene level changes during differentiation (Driscoll et al., 2015; Szczesny \& Mauck, 2017). Foundational studies have begun the process of understanding gene-level changes associated with changes to cell shape (Jain et al., 2013). Studies connecting cytoskeletal changes to nuclear changes have provided mechanical insights for the basis of these gene-level changes (Versaevel et al., 2012; Chen et al., 2015).

Given the mechanical changes of the cell during the differentiation process, which is well known to be highly regulated by gene level changes, it is of interest to understand how the mechanical changes can in turn influence the nuclear material. Research points to the Linker of Nucleoskeleton and Cytoskeleton Complex (LINC) containing KASH (Klarsicht Anc- 1Syne-1Homology) and SUN (Sad1pUnc-84) proteins as crucial in the mechanical coupling of the nuclear matrix (the lamina) and cellular cytoskeleton (Kim et al., 2015). As such, the aim of this paper is to provide a correlation and causation between the cytoskeletal mechanical changes during the differentiation process and the nuclear morphology, most particularly nuclear elongation, as a result of neurite formation and cellular elongation. The methods utilize the well-known SH-SY5Y neuroblastoma cell line, differentiated through an 
established retinoic acid based protocol, that forms neurites across 10 days. The mechanical coupling of cellular elongation and nuclear elongation during Retinoic Acid mediated neural differentiation is not well explored in the literature. By providing information that relates the mechanics of the cell during differentiation with the mechanical changes of the cell nucleus, it is possible to make a reciprocal connection that relays the effect of differentiation on gene level processes. Figure 1 provides an illustrative example of the phenomenon being presented in this study. The LINC mediated coupling of the mechanics of the cell body and nucleus is highly important and of key significance in cellular engineering. This study is one of the first quantitative characterizations of correlation and relatedness of cellular elongation and nuclear elongation during the process of RA differentiation in SH-SY5Y neural cells.

\section{MATERIAL AND METHOD}

SH-SY5Y neuroblastoma cells (Sigma Aldrich, USA) are seeded at a recommended density of $15,000 \mathrm{cells} / \mathrm{cm}^{2}$ in tissue culture treated 6 well plates. They are grown for 48 hours in FBS (Sigma Aldrich, USA) supplemented EMEM (15\% FBS, 2 mM Glutamine, Pen/Strep treated, all obtained from Sigma Aldrich, USA) as provided by standard protocols (Shipley et al., 2016). After the $48 \mathrm{~h}$ time point, the first day of the 10 day protocol starts, in which cells are grown in the base medium for Day 0. Following this initial growth, the cells reach confluency, and are pushed to neurite differentiation through introduction of serum deprived, RAenhanced EMEM (10 $\mu$ M Retinoic Acid from Sigma Aldrich, USA, $2.5 \%$ FBS, $2 \mathrm{mM}$ Glutamine, Pen/Strep treated). This medium is utilized from Day 1 through Day 9.
In order to visualize morphological changes to the cell during the differentiation process in both the cell body and the nucleus, F-actin and chromatin staining is performed using conjugated Phalloidin (Biotium, USA) and 4',6diamidino-2-phenylindole (Life Technologies, USA). In order to perform staining, cells are washed 3 times with PBS buffered saline solution, then fixed using $4 \%$ formaldehyde in PBS. The formalin fixation is performed at $5 \% \mathrm{CO}_{2}$ and $37^{\circ} \mathrm{C}$ for $30 \mathrm{~min}$ and is then follows with PBS rinsing 3 times. The fixed cells are stained first with AlexaFluor-488 conjugated Phalloidin, then with 4,,6- diamidino-2phenylindole, abbreviated as DAPI, in this order. The staining protocols and storage of dyes follow closely with the recommendations of the vendors from whom they are obtained (Adams \& Pringle, 1991; Stuart \& Cole, 1999). Cells are imaged with the Olympus microscopy system using a filtered broadband light source to obtain fluorescence images. DAPI is imaged at 352-402/417-477 nm excitation/ emission and Phalloidin is imaged at 467-498/513-556 nm excitation/emission (FITC) with a standard Olympus filter cube system.

For each time point, at least 3 separate samples of cells are analyzed from independent, replicate preparations. For the same region of cells, images of F-actin staining and chromatin staining are obtained. Quantification involves tracing the longest portion of the cell body as a measure of cellular elongation (Vishavkarma et al., 2014). Similarly, for the same cells in the DAPI stained images, nuclear elongation is quantified as the spread of the nucleus in the longest direction (Vishavkarma et al.). Statistical analysis is performed using MATLAB R2019a. F-actin and nuclear quantification is performed through tracing and measurement on Image $\mathrm{J}$ open source from the National Institutes of Health (NIH).

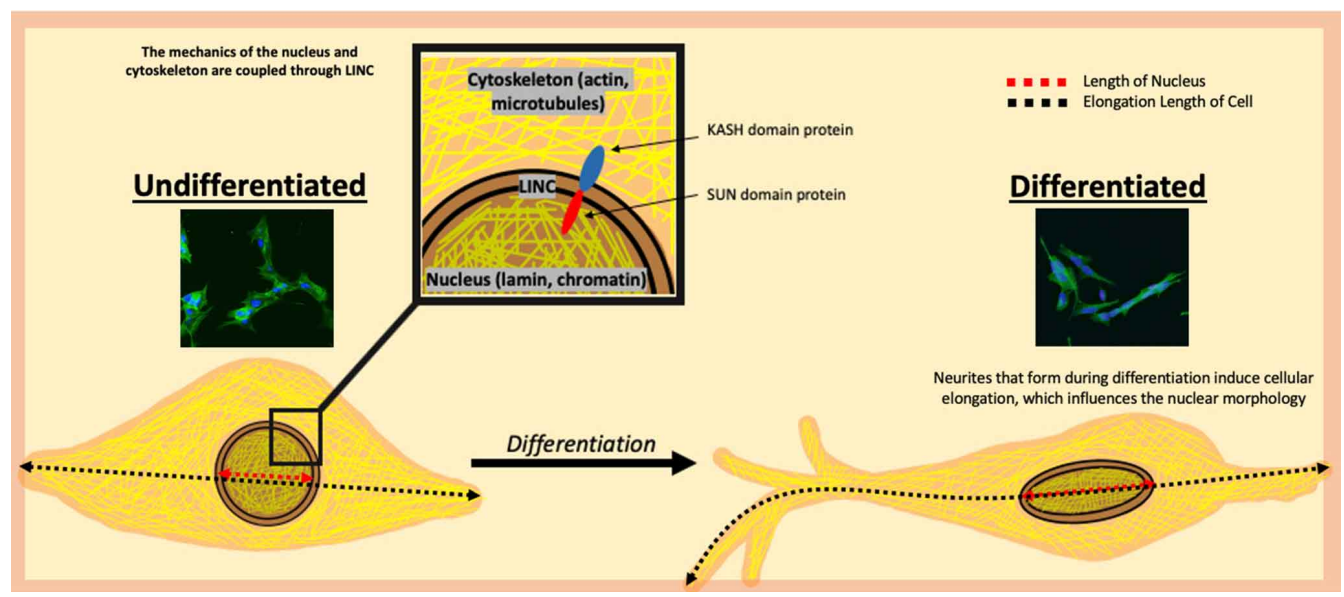

Fig. 1. Neural differentiation causes neurites to appear, and this is followed by elongation. Black dotted line shows the cellular elongation length and red dotted line show nuclear elongation length. It can be seen that the cell elongation due to the emergence of neurites causes nuclear elongation. This phenomenon is governed by the LINC (Linker of Nucleoskeleton and Cytoskeleton Complex) which is represented schematically in the detail box at the top of the figure. 


\section{RESULTS}

Neurites emerge during RA mediated SH-SY5Y differentiation. This study verifies that RA supplementation causes the emergence of neurites, which are not highly pronounced at $22.73 \pm 13.60 \mu \mathrm{m}$ in length on average at day 0 ,
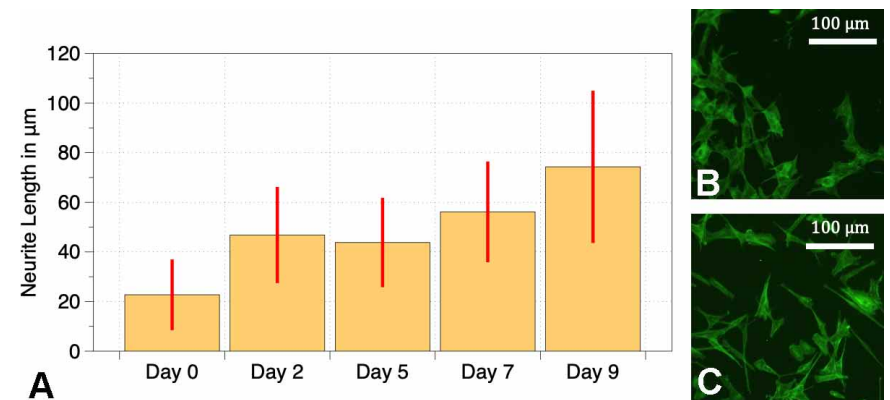

Fig. 2. Neurite outgrowth is quantified over differentiation time points. a. Neurite lengths are provided as average and standard deviation in bar graph. b. Cells during day 0 of differentiation shown. Very few neurites visible. c. Cells during day 9 of differentiation following RA supplementation shown. Many neurites visible. and increasing to $74.32 \pm 30.04 \mu \mathrm{m}$ in length on average at Day 9. Results are summarized in Figure 2.

Nuclear elongation has small but significant increase across time points during neural differentiation. As shown in Figure 3, nuclear elongation does increase across time points during the differentiation process but is not as substantial as the extent of the neuritic extensions. The starting point nuclear elongation is an average of $17.51 \pm 2.71 \mu \mathrm{m}$ for a total of 44 cells across three trials at day 0 . Statistically significant increases in nuclear elongation are seen for day 7 and day 9 at an $\alpha$ $=0.05$. Lengths for each time point are summarized in Figure 3. On day 9, nuclear elongation is an average of $23.26 \pm 3.10 \mu \mathrm{m}$ for a total of 54 cells across three trials. Figures $3 \mathrm{c}$-e show nuclei stained with DAPI at various time points across differentiation.

Cellular elongation increases significantly and substantially across time points during neural differentiation. As shown in Figure 4, cellular elongation increases across time points significantly and substantially
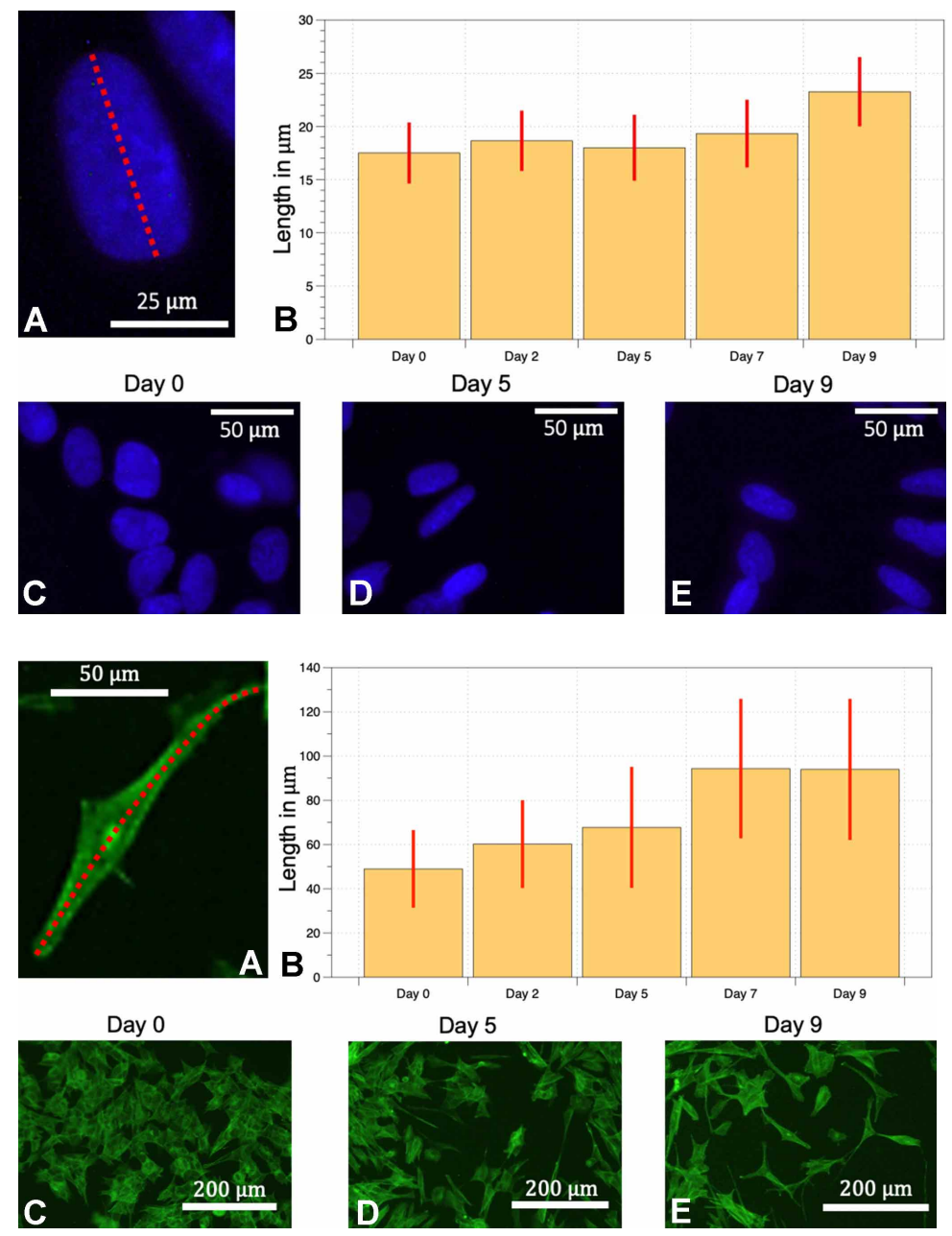

Day 5
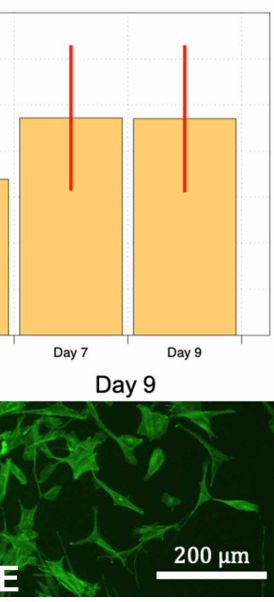

Fig. 3. Nuclear elongation during differentiation is quantified over time. a. Representative nuclear elongation length traced. b. Average and standard deviation depicted across differentiation time points for nuclear elongation in microns. c. Representative image of Day 0 , pre-differentiation cell nuclei stained with DAPI. d. Representative image of Day 5 RA differentiating cell nuclei stained with DAPI. e. Representative image of Day 9 RA differentiating cell nuclei stained with DAPI.

Fig. 4. Cellular elongation during differentiation is quantified over time. a. Representative cellular elongation length traced. b. Average and standard deviation depicted across differentiation time points for cellular elongation in microns. c. Representative image of Day 0 , pre-differentiation cell body stained with Phalloidin. d. Representative image of Day 5 RA differentiating cell body stained with Phalloidin. e. Representative image of Day 9 RA differentiating cell body stained with Phalloidin. 
as determined by the RA induced neurite formation. On day 0 , cellular elongation is an average of $48.97 \pm 16.85 \mu \mathrm{m}$ for a total of 44 cells across three trials. On day 9 , cellular elongation is an average of $93.96 \pm 31.20 \mu \mathrm{m}$ for a total of 54 cells across three trials. This trend proceeds gradually across time points, with both day 7 and day 9 at the peak values of cellular elongation for the time points tested in this study. Statistical significance is tested at an $\alpha=0.05$,with statistically significant changes from baseline observed over time.

Undifferentiated cells have no statistically significant correlation between nuclear elongation and cellular elongation. As seen in Figure 5, the relationship between nuclear elongation and cellular elongation is shown in undifferentiated cells at day 0 . The correlation coefficient of 0.1622 is statistically insignificant with a p-value of 0.2928 . This serves as a base claim that precedes any further investigation of correlation between nuclear elongation and cellular elongation. Since there is no statistically significant correlation to start with, any further correlation that is observed will have been acquired through the differentiation process.

Differentiating neural cells display a statistically significant correlation between nuclear elongation and cellular elongation. As seen in Figures 5, following RA differentiation, time points of days 2, 5, 7, and 9 all demonstrate significant correlation, with correlation coefficients of $0.42,0.38,0.33$, and 0.32 respectively, with a p-value of significance $<0.05$. Full statistical test results and samples sizes are shown in Table I. Comparing these results to the results from the previous subsections suggests that not only is nuclear elongation increasing with further differentiation time points, but also that the cellular elongation is causative to this given a statistically significant correlation only following differentiation induction. When analyzing results with all cells across all time points following differentiation, the correlation is also significant, with a coefficient of 0.4498 with a p-value of $<0.0005$ for 202 cells across multiple trials as shown in Figure 6.

Slope $=1.01$

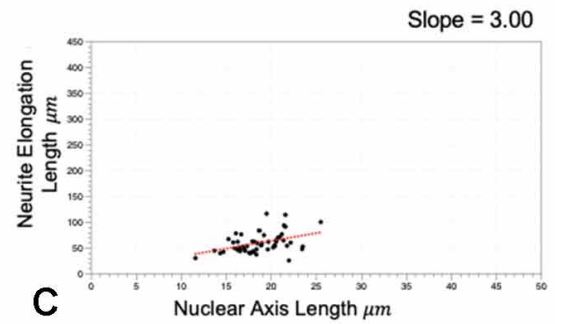

\section{B}

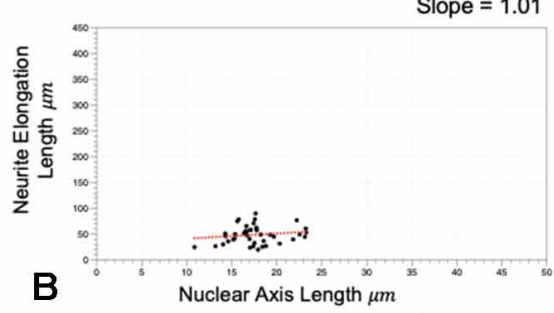

Slope $=3.36$
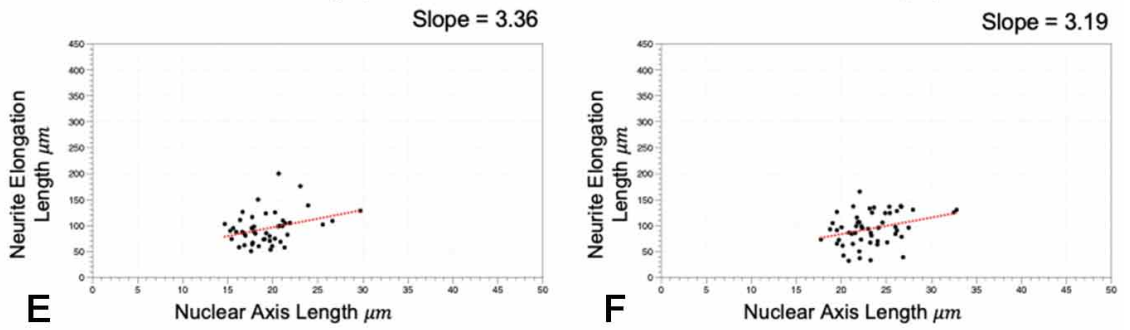

$\mathbf{F}$

D

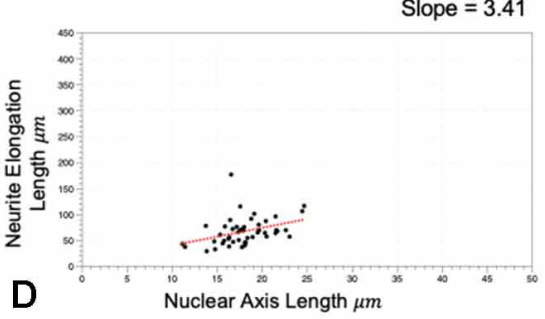

Fig. 5. Across Time Correlation of Nuclear Elongation and Cellular Elongation a. Correlation of neurite driven cellular elongation length and nuclear elongation length with linear fit provided across all differentiation time points. b. Correlation for Day 0. c. Correlation for Day 2. d. Correlation for Day 5. e. Correlation for Day 7. f. Correlation for Day 9.

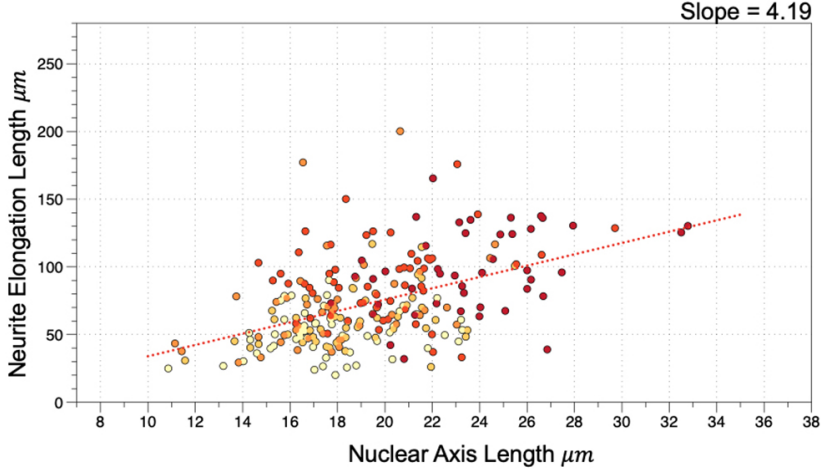

Fig. 6. Correlation of neurite driven cellular elongation length and nuclear elongation length with linear fit provided for all differentiation time points. Yellow to red gradient colored data points represent time points from Day 0 to Day 9.

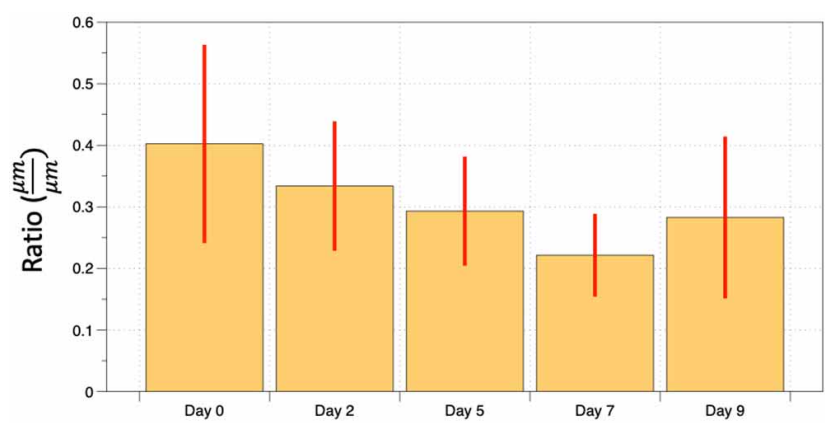

Fig. 7. Nuclear elongation to cellular elongation ratio provided across differentiation time points with error bars as standard deviation. 
Elongation ratio has an overall decrease across time points. In order to compare the effect of differentiation on cellular elongation with the effect of differentiation on nuclear elongation, the ratio of the length of the nucleus in microns to the length of the cellular elongation in microns was taken on a per cell basis. This is designated as the nuclear elongation to cellular elongation ratio. The results of this analysis are shown graphically with error bars in Figure 7. Statistical testing from ANOVA is available in Table II, tested at a significance level of $\alpha=0.05$. It is noted that this ratio decreases across time, leading to the conclusion that, while there is mechanical coupling between the neurite extensions and nucleus, the rate of growth of the cell periphery at the neurite is much faster than the rate of elongation of the nucleus. At day 0, the ratio is $0.40 \pm 0.16 \mu \mathrm{m}$, compared to day 7 and 9 with a ratio of $0.22 \pm 0.06 \mu \mathrm{m}$ and $0.28 \pm 0.13$ $\mu \mathrm{m}$ respectively, significantly different from day 0 at a $\mathrm{p}$ value $<0.05$.

Table I. Nuclear elongation and cellular elongation correlation results for time points in differentiation study.

\begin{tabular}{lcccccc}
\hline & $\begin{array}{c}\text { Number of } \\
\text { Cells }\end{array}$ & $\begin{array}{c}\text { Cellular Elongation } \\
\text { Length }(\mu \mathrm{m})\end{array}$ & $\begin{array}{c}\text { Nuclear Elongation } \\
\text { Length }(\mu \mathrm{m})\end{array}$ & $\begin{array}{c}\text { Average Neurite } \\
\text { Length }(\mu \mathrm{m})\end{array}$ & $\begin{array}{c}\text { Correlation } \\
\text { Coefficient }\end{array}$ & P-value \\
\hline Day 0 & 44 & $48.97 \pm 16.84$ & $17.51 \pm 2.71$ & $22.73 \pm 13.60$ & 0.1622 & 0.2928 \\
Day 2 & 54 & $60.17 \pm 19.14$ & $18.65 \pm 2.68$ & $46.83 \pm 18.72$ & 0.4199 & 0.0016 \\
Day 5 & 47 & $67.75 \pm 26.63$ & $18.01 \pm 2.94$ & $43.80 \pm 17.35$ & 0.3795 & 0.0091 \\
Day 7 & 47 & $94.33 \pm 30.83$ & $19.33 \pm 3.03$ & $56.14 \pm 19.66$ & 0.3299 & 0.0245 \\
Day 9 & 54 & $93.96 \pm 31.20$ & $23.26 \pm 3.10$ & $74.32 \pm 30.04$ & 0.3175 & 0.0193 \\
\hline
\end{tabular}

Table II. ANOVA Tukey HSD Post-hoc results for nuclear to cellular elongation ratio across experimental time points.

\begin{tabular}{cc}
\hline Comparison Group & P-Value \\
\hline Day 0 \& Day 2 & 0.0208 \\
Day 0 \& Day 5 & 0.0001 \\
Day 0 \& Day 7 & 0.0000 \\
Day 0 \& Day 9 & 0.0000 \\
Day 2 \& Day 5 & 0.3887 \\
Day 2 \& Day 7 & 0.0000 \\
Day 2 \& Day 9 & 0.1471 \\
Day 5 \& Day 7 & 0.0239 \\
Day 5 \& Day 9 & 0.9919 \\
Day 7 \& Day 9 & 0.0619 \\
\hline
\end{tabular}

\section{DISCUSSION}

The presented results allow for a few conclusions. In RA differentiated neurons, nuclear elongation is observed across time. This is somewhat expected given that studies showing the influence of cell spreading in epithelial and other cell types also show changes to the nuclear morphology (Vishavkarma et al.). Second, the extension of the nucleus is strongly correlated with the extension of the cell body on a per cell basis only following RA mediated neural differentiation, but not preceding it. This provides a very unique causative basis for nuclear elongation - in fact, the process of neurite formation is a cause for the elongation of the nucleus given the statistically significant correlation, onset only by the process of RA differentiation. Furthermore, Figure 5 shows that there is a statistically significant decrease in the ratio of nuclear elongation and cellular elongation, suggesting that these two factors are not perfectly coupled. This is to be expected as there is some spatial mechanical decoupling between the more centrally located area of the nucleus, and the peripheral neuritic extensions. This conclusion supports a causative relationship; Cellular elongation can trigger nuclear elongation. It seems that the end time points to an increase in the ratio (though Day 7 and Day 9 are not statistically significant in their difference at an $\alpha=0.05)$. This could suggest a potential for the mechanical coupling to itself have a time course. This could also suggest that as neurite extension lowers in rate, the nuclear elongation may or may not start to increase at later time points in differentiation due to delayed mechanical coupling. This is an area for future investigation.

It is known in the literature that the nuclear envelope receives mechanical information about the cell body through specific and nonspecific coupling of the nuclear matrix and the cytoskeleton. KASH and SUN proteins are crucial in the literal coupling of the nuclear matrix and the cytoskeleton, through the Linker of Nucleoskeleton and Cytoskeleton Complex (LINC) (Kim et al.). This study provides various insights into the time course and extent of the mechanical coupling through LINC by KASH and SUN and similar protein complexes through the process of neural differentiation. A potential future direction involves assessing nuclear strain through super-resolution imaging of GFP tagged LINC complexes to look at the elongation and movement across time of the nuclear envelope due to strain induced by differentiation. This will allow for a direct threedimensional measure of strain across time with automated image acquisition at a set acquisition rate and time with cells embedded and growing in a three-dimensional matrix. 
Investigation of various gene level mechanisms associated with nuclear strain and elongation is of future interest. Points of exploration include in vitro lamin and LINC knock-outs (Liu et al., 2019). Transcriptomic and proteomic studies of various neural differentiation markers will be analyzed under different initiators of nuclear strain (Szczesny \& Mauck; Shang et al., 2018; Burke et al., 2020).

\section{CONCLUSIONS}

Image quantification during differentiation holds immense promise towards uncovering important mechanical changes that underlie the process of cellular development. In this study, neural cell differentiation is shown to cause nuclear strains that are correlated with the neuritic elongation of the cell. This is one of the first studies to quantify the correlation between nuclear elongation and cellular elongation during the process of differentiation and show that prior to differentiation, these two quantities are uncorrelated, and then they become correlated during and through the differentiation process. By utilizing this information, this study supports the hypothesis that the LINC complex does propagate the mechanical changes associated with peripheral neurite development to the nuclear envelope. Further staining specific to the nuclear envelope using fluorescently tagged single molecules imaged with three-dimensional super-resolution microscopy will be explored in a longer time course study. Planned transcriptome and proteome studies will help to uncover molecular mechanisms.

BALASUbRAMANiAn, P. S. El alargamiento del núcleo se correlaciona con el alargamiento celular inducido por neuritas durante la diferenciación de las células neuronales sh-sy5y. Int. J. Morphol., 39(2):548-553, 2021.

RESUMEN: La diferenciación celular es un proceso altamente regulado que tiene vastas implicaciones para la mecánica de la célula. La interacción entre los cambios mecánicos citoesqueléticos inducidos por la diferenciación y la tensión en el núcleo es una causa potencial de cambios a nivel genético. Este estudio explora los cambios mecánicos en las células neurales SH-SY5Y durante la diferenciación mediada por el ácido retinoico (RA) durante los días 0 a 9. Los resultados sugieren que el alargamiento celular aumenta 1,92 veces durante un período de diferenciación de 10 días, de 48,97 \pm 16,85 $\mu \mathrm{m}$ a 93,96 $\pm 31,20 \mu \mathrm{m}$ en 3 ensayos repetidos y en múltiples células analizadas en Image J. El alargamiento nuclear aumenta menos sustancialmente de 17,51 $\pm 2,71 \mu \mathrm{m}$ a 23,26 $\pm 3,10 \mu \mathrm{m}$ durante 3 ensayos repetidos y en múltiples células. Los resultados son estadísticamente significativos a un nivel de significancia de $\mathrm{a}=0,05$. Esta investigación es uno de los primeros estudios en demostrar que durante el proceso de diferenciación neural mediada por RA en las células neurales SH-SY5Y, el alargamiento nuclear inicialmente no se correlaciona significativamente con el alargamiento celular, pero se correlaciona durante el proceso de diferenciación con un coeficiente de correlación global de 0,4498 a un nivel de significancia de $\alpha=0,05$. Dado el curso temporal de los cambios mecánicos y el acoplamiento conocido entre el citoesqueleto y la lámina nuclear, este estudio sugiere una relación causal y correlativa entre el alargamiento celular impulsado por neuritas y el alargamiento nuclear durante la diferenciación neural.

PALABRAS CLAVE: Diferenciación celular; Núcleo; Citoesqueleto; Mecánica celular; Imágenes.

\section{REFERENCES}

Adams, E. M. \& Pringle, J. R. Staining of actin with fluorochrome-conjugated phalloidin. Methods Enzymol., 194:729-31, 1991.

Burke, E. E.; Chenoweth, J. G.; Shin, J. H.; Collado-Torres, L.; Kim, S. K.; Micali, N.; Wang, Y.; Colantuoni, C.; Straub, R. E.; Hoeppner, D. J.; et al. Dissecting transcriptomic signatures of neuronal differentiation and maturation using iPSCs. Nat. Commun., 11(1):462, 2020.

Chen, B.; Co, C. \& Ho, C. C. Cell shape dependent regulation of nuclear morphology. Biomaterials, 67:129-36, 2015.

Driscoll, T. P.; Cosgrove, B. D.; Heo, S. J.; Shurden, Z. E. \& Mauck, R. L. Cytoskeletal to nuclear strain transfer regulates YAP signaling in mesenchymal stem cells. Biophys. J., 108(12):2783-93, 2015.

Jain, N.; Venkatesan Iyer, K.; Kumar, A. \& Shivashankar, G. V. Cell geometric constraints induce modular gene-expression patterns via redistribution of HDAC3 regulated by actomyosin contractility. Proc. Natl. Acad. Sci. U. S. A., 110(28):11349-54, 2013.

Kim, D. I.; Birendra, K. C. \& Roux, K. J. Making the LINC: SUN and KASH protein interactions. Biol. Chem., 396(4):295-310, 2015.

Liu, H.; Li, D. M.; Zhu, L. Y.; Lai, L. J.; Yan, W. Y.; Lu, Y. H.; Wei, Y.; Huang, Y. Q.; Fang, M.; Su, Y. G. Research on the knockout of LMNA gene by CRISPR/Cas9 system in human cell lines. Yi Chuan, 41(1):66-75, 2019.

Peng, R.; Yao, X. \& Ding, J. Effect of cell anisotropy on differentiation of stem cells on micropatterned surfaces through the controlled single cell adhesion. Biomaterials, 32(32):8048-57, 2011.

Shang, Z.; Chen, D.; Wang, Q.; Wang, S.; Deng, Q.; Wu, L.; Liu, C.; Ding, X.; Wang, S.; Zhong, J.; et al. Single-cell RNA-seq reveals dynamic transcriptome profiling in human early neural differentiation. Gigascience, 7(11):giy117, 2018.

Shipley, M. M.; Mangold, C. A. \& Szpara, M. L. Differentiation of the SHSY5Y human neuroblastoma cell line. J. Vis. Exp., (108):53193, 2016.

Stuart, K. R. \& Cole, E. S. Nuclear and cytoskeletal fluorescence microscopy techniques. Methods Cell Biol., 62:291-312, 2000.

Szczesny, S. E. \& Mauck, R. L. The Nuclear Option: evidence implicating the cell nucleus in mechanotransduction. J. Biomech. Eng., 139(2):021006102100616, 2017.

Versaevel, M.; Grevesse, T. \& Gabriele, S. Spatial coordination between cell and nuclear shape within micropatterned endothelial cells. Nat. Commun. 3:671, 2012.

Vishavkarma, R.; Raghavan, S.; Kuyyamudi, C.; Majumder, A.; Dhawan, J. $\&$ Pullarkat, P. A. Role of actin filaments in correlating nuclear shape and cell spreading. PloS One, 9(9):e107895, 2014.

Zhang, K.; Arranja, A.; Chen, H.; Mytnyk, S.; Wang, Y.; Oldenhof, S.; van Esch, J. H. \& Mendes, E. A nano-fibrous platform of copolymer patterned surfaces for controlled cell alignment. RSC Adv., 8(39):21777-85, 2018.

Corresponding Author:

Priya S. Balasubramanian

Electrical and Computer Engineering

Cornell University

Ithaca, 14850

NY - USA

Email: psb79@cornell.edu

Received: 07-09-2020

Accepted: 07-12-2020 